Original Article

\title{
Functionality in Women with Breast Cancer: The Use of International Classification of Functioning, Disability and Health (ICF) in Clinical Practice
}

\author{
Flávia Nascimento de Carvalho ${ }^{1)}$, Anke Bergmann ${ }^{1)^{*}}$, Rosalina Jorge Koifman ${ }^{2)}$ \\ 1) National Cancer Institute: Rua André Cavalcanti, 37, Centro, Rio de Janeiro, RJ, Brazil \\ 2) National School of Public Health Sergio Arouca, Brazil
}

\begin{abstract}
Purpose] The aim of this study was to evaluate the functionality of women diagnosed with breast cancer according to the International Classification of Functioning, Disability and Health (ICF). [Subjects and Methods] This was a cross-sectional study. We applied instruments consistent with the summary of ICF codes for breast cancer: quality of life questionnaire (WHOQOL), upper limb symptoms and function (DASH), social support, physical examination and functional medical record data. [Results] The study included 105 women who were 55 years old and subjected to surgical treatment within an average of 1.63 year previously. The 'function' component considered in the WHOQOL, the DASH and physical examination. There were high prevalences of positive responses for most codes, and only b130, d430, d445, d640, d650, d920 and codes of environmental factors considered by the Social Support Questionnaire showed high prevalences of negative responses $(47.6 \%, 61 \%, 43.8 \%$, $63.8 \%, 56.2 \%, 52.4 \%$, and $35.2 \%$, respectively). [Conclusion] There was a lower prevalence of disability, with the exception of issues related to strenuous activity and load. Some findings showed conflicting results between different instruments that measure the same code, and studies that propose more accurate tools and are able to consider the ICF codes specific to this pathology are necessary.

Key words: Breast cancer, Functionality and disability
\end{abstract}

(This article was submitted Oct. 29, 2013, and was accepted Dec. 5, 2013)

\section{INTRODUCTION}

Breast cancer is the most common cancer among wom$\mathrm{en}^{1)}$, and its treatment can be local and/or systemic. Treatment with surgery, chemotherapy, hormone therapy, and radiotherapy reduces the risk of local recurrence and, distant metastasis and increases overall survival ${ }^{2}$. However, treatment of breast cancer is associated with a wide range of functional impairments resulting from complications such as lymphedema, pain syndromes, peripheral nerves injury and limited range of motion ${ }^{3-6)}$.

A significant proportion of women suffer from anxiety, depression, fatigue, sleeping problems, and sexual and body image disturbances that affects the quality of life of these patients ${ }^{7)}$. These injuries are referring to information on morbidity, which does not allow us to determine the degree of functionality that an individual shows ${ }^{4,8)}$.

Functionality, according to World Health Organization (WHO), is a complex term that involves the alteration of a structure and its function, as well as the limitations found in performing certain activities and restrictions on participa-

*Corresponding author. Anke Bergmann (E-mail: abergmann@inca.gov.br)

(C2014 The Society of Physical Therapy Science. Published by IPEC Inc. This is an open-access article distributed under the terms of the Creative Commons Attribution Non-Commercial No Derivatives (by-ncnd) License $<$ http://creativecommons.org/licenses/by-nc-nd/3.0/>. tion in life situations. Quality of life instruments are used to describe and evaluate functioning in clinical practice. Because it is a complex term that involves different contexts, the WHO developed the International Classification of Functioning, Disability and Health (ICF $)^{9)}$. Since quality of life questionnaires and the ICF represent two different perspectives regarding functionality and health, they are expected to be used simultaneously both in clinical practice $^{10)}$.

If the ICF is a tool that comes closest to the definition of functionality, its introduction into clinical practice is necessary. According to Cieza and Stucki ${ }^{10)}$, to access health status, items from different instruments can be linked to the corresponding ICF categories and components (body functions and structures, activities and participation, contextual factors).

Brach et al. ${ }^{11)}$ related codes of ICF that were more prevalent in women diagnosed with breast cancer. The instruments validated for the Brazilian population, confronted with these codes and considered the most comprehensive, were applied to women with breast cancer ${ }^{12}$. Based on the application of these instruments, we aim to describe use of ICF in clinical practice and to identify the prevalence of disability in our population.

\section{SUBJECTS AND METHODS}

This was a cross-sectional study in women undergoing 
surgical treatment for breast cancer at the Brazilian National Cancer Institute.

We included women who underwent surgical treatment for breast cancer, with a minimum follow-up of one year post surgery. Patients with an adjuvant treatment, disease evolution (local or distant), or history of cognitive impairment or functional impairment of an upper limb prior to breast cancer diagnosis were excluded.

The women were identified in an outpatient physiotherapy service among those in routine follow-up after surgery between October 2011 and April 2012. Routine follow-up includes standardized assessments conducted at different times during the follow-up period ${ }^{13)}$. The eligible women were invited to participate in the study by signing an informed consent form.

Sample estimation was considered with a confidence interval of $95 \%$, a statistical power of 0.80 , the functionality as the dependent variable, and lymphedema as the independent variable. Estimating that $30 \%$ of the population had lymphedema and $10 \%$ of the unexposed group have this alteration, would require the inclusion of 83 individuals. For this calculation, we used the Epi Info 3.5.2.

During the period for recruitment of patients, 105 women's fulfilled the eligibility criteria for this study.

Data were collected by interviews, physical examination, and analysis of patient records. Outcomes of interest included functional alterations consequent to treatment of breast cancer, according to the constructs of the ICF more prevalent in people with breast cancer ${ }^{11)}$.

Sociodemographic variables were obtained from interviews, and the following data were collected: date of birth, marital status, education, social security ties, net monthly family income (classified into classes A to D) ${ }^{14)}$; number of people dependent on family income, and weight and height.

The following clinical and tumor data were obtained from the patient records: neoadjuvant and adjuvant treatment (chemotherapy, hormone therapy, and radiotherapy, surgical treatment (date, breast and axillary surgery, and breast reconstruction); pathological staging (pTNM) categorized as initial stage (I, IIA, and IIB) and advanced (IIIA and IIIB) ${ }^{15)}$; and wound complications (dehiscence, necrosis, infection, and seroma).

The following data were collected in a physical examination: muscle strength as measured using a hydraulic dynamometer, performed three times on each member, with an interval of 15 seconds between each test and the best measure of three trials adopted ${ }^{16,17)}$, arm volume estimated by the truncated cone formula, with lymphedema being defined as a difference in volume between arms of at least $200 \mathrm{~mL}^{6}$ ); self-reported symptoms of pain, heaviness, or swelling in the $\operatorname{arm}^{18,19)}$; and winged scapula defined by assessment of the scapular positioning of both shoulders in a resting posture and during active resistance movement. Hypotonia of the serratus anterior muscle was identified by projection of the internal board and/ or the inferior angle of the scapula ipsilateral to surgery ${ }^{20)}$.

Evaluation of the arch of movement (ADM) was performed by observation by a physiotherapist, who classified $\mathrm{ADM}$ as complete ADM, functional movement (when the full width of movement is not obtained but it is possible to perform activities with the member) and incomplete $\mathrm{ADM}^{21)}$.

The sensitivity during the intercostobrachial nerve course was evaluated by touching of monofilaments. The presence of protecting sensitivity and the deep pressure (zero degree of disability) was considered normal when the positive answers to the branches $0.05 \mathrm{~g}$ (green) or $0.02 \mathrm{~g}$ (blue) or yet $2 \mathrm{~g}$ (violet). The positive answers to the branches $4 \mathrm{~g}$ (red), $10 \mathrm{~g}$ (orange), or absence of answer to the branch $300 \mathrm{~g}$ (red magenta) was defined as degree 1 of disability ${ }^{22}$.

The WHOQOL-bref questionnaire (abbreviated version of the World Health Organization Quality of Life) was used to examine physical health, psychological, social relations, and environment areas and comprised 26 questions regarding the last two weeks; the questionnaire was applied by a qualified interviewer. In this instrument, the scores of the domains were organized on a positive scale, meaning that higher scores indicated better quality of life. The average of the scores for the items of each area are used for calculation for the area and are multiplied by 4 in order to be compatible with the scores of the WHOQOL-100. For the calculation, the Statistical Package for the Social Sciences (SPSS) was used $^{23)}$.

The Social Support Questionnaire (SSQ) contains five dimensions that include nineteen questions about social support: material, affective, positive social interaction, emotional, and information. For all the questions, five options are presented for answers, and low scores are related to low social support ${ }^{24)}$. For the SSQ calculation, the tertiles of each area were used ${ }^{25}$.

Measurement of the functions and symptoms of the superior member was performed with the DASH (Disability Arm Shoulder and Hand), an instrument that contains thirty questions regarded to measure symptoms and physical and social functions. At least 27 items should be answered, and each answered question has a maximum value of five, which is transformed into a score out of one hundred for comparison with other scales by subtracting one and multiplying by 25 . A high score means great disability ${ }^{26)}$.

A descriptive analysis of the patients' characteristics was performed using the measures of central tendency and dispersion for the continuous variables and relative frequency and absolute frequency for the categorical variables.

Quality of life and presence of pain in the superior member were separated in three categories: positive or favorable answers; intermediate answers; and negative or unfavorable answers, according to their approach. In WHOQOL and DASH questionnaires, the first category was considered negative or unfavorable, and the last one was considered positive or favorable. Three questions in the WHOQOL get the opposite. The third, the fourth and the twenty-sixth questions present as first category the positive favorable answers and on the last one the negative or unfavorable ones. For data analysis, the SPSS version 17.0 was used.

The study was approved by the Ethics and Research Committee of the National School of Public Health and registered under the number 288/11 and was also approved by the National Cancer Institute and registered under the 
Table 1. Descriptive analysis of continuous variables

\begin{tabular}{lrrrrr}
\hline Variables & Mean & SD & Median & Minimum & Maximum \\
\hline Age (year) & 55.82 & 11.61 & 54.00 & 34.00 & 79.00 \\
Family income (R\$) & $1,693.00$ & $2,002.70$ & $1,200.00$ & 100.00 & $14,000.00$ \\
Number of dependents & 2.44 & 1.32 & 2.00 & 1.00 & 6.00 \\
BMI & 27.80 & 4.30 & 27.21 & 20.01 & 42.61 \\
Follow-up after surgery (year) & 1.85 & 1.36 & 1.63 & 1.00 & 11.80 \\
Difference volume of the arms (ml) & 107.27 & 9.18 & 106.00 & 87.50 & 140.00 \\
\hline
\end{tabular}

$\mathrm{BMI}=$ body mass index, $\mathrm{SD}=$ Standard deviation

number 84/11.

\section{RESULTS}

According to the criteria of this study, a volunteer was discarded for presenting an active disease at the moment of the interview; as a result, we had 105 women who fulfilled the criteria for inclusion. The descriptive data of these women are shown in Table 1 (continuous variables) and Table 2 (categorical variables).

The subjects had a mean of age of 55 years (SD 11, 61); $61 \%$ of them were 50 years old, and $48.6 \%$ of them had a partner at the time of the interview. The educational level was considered low in $52.4 \%$ of the women, and $60 \%$ reported housewife as their occupation. About $81 \%$ of them were unemployment. Regarding family income, $54.3 \%$ of them received 2 minimum wages or less, and $53.4 \%$ of them were categorized into class $\mathrm{E}$. The median of family income was $\$ 2,689.00$, with family income ranging between $\$ 224.08$ and $\$ 31,370.00$. From the income-related data, it was found that the mean number of dependents was 2 (SD 1.3).

About $45 \%$ of thesubjects were overweight, and $27 \%$ were considered obese, with the median body mass index (BMI) being was 27.2 (20.0-42.61). At the time of diagnosis, $69.5 \%$ presented the initial stage (I to IIB). At the time of the interview, $34.3 \%$ were more than two years after surgery. Regarding surgical treatment, $78 \%$ of the women had undergone mastectomy, and $72 \%$ had undergone axillary dissection. Regarding adjuvant treatment $25.2 \%$ were subjected to chemotherapy, radiotherapy, and hormone therapy, and $27.3 \%$ were subjected to radiotherapy and hormone therapy (data were not presented). Of the women who were subjected to mastectomy, $6 \%$ had breast reconstruction, and $50 \%$ of these subjects received silicon prostheses; $33 \%$ received transposition of the rectus abdominis muscle (TRAM). Among the post surgical complications, $43 \%$ presented seroma, and $29 \%$ presented wound dehiscence and necrosis. In the physical exam, comparison of the indirect volumes of the upper members revealed a difference of $106 \mathrm{~mL}(87.50-140.00 \mathrm{~mL})$, which indicated the absence of lymphedema in this population.

Upon analyzing the instruments from the perspective of functionality, we observed that the 'function' component was considered in the WHOQOL, the DASH, and the physical examination. The WHOQOL considered nine codes from the "body functions" component, nine codes from "activities and participation" and 12 codes from the contextual factors of the ICF.

As seen in Fig. 1, for code b126 (temperament and personality functions), we found a prevalence of positive answers for two questions in the WHOQOL, with the prevalences being $55.2 \%$ and $62.7 \%$. This was also seen for code b130 (energy and drive functions); however, regarding the energy necessary on a daily basis, we observed a higher prevalence of negative and intermediate answers (52.4\%). The question that measured code b280 (sensation of pain) was answered in a positive way by $53.8 \%$ of the women. For code b1801 (body image), we found a prevalence of positive answers of $59.1 \%$.

Of the 26 questions in this questionnaire, 11 considered code b152 (emotional functions) and showed higher prevalences of positive answers, which ranged from 47 to $82 \%$. Codes b134 (sleep functions), b180 (experience of self and time functions), and b640 (sexual functions) and b670 (sensations associated with genital and reproductive functions) could be measured by questions that were also able to measure code b152, and we obtained prevalences of positive answers for each of them: $63.8,74.3$ and $47.1 \%$ respectively (Fig. 1).

In the WHOQOL, we could also find positive answers for codes $\mathrm{d} 720$ (complex interpersonal interactions), d750 (informal social relationships), d760 (family relationships), e315 (support and relationship from extended family), e320 (support and relationship with friends), e325 (support and relationship with acquaintances, peers colleagues, neighbors, and community members), which were considered by the same question. Codes e 320 and e 420 may also be measured by another question from the questionnaire, which showed a prevalence of positive answers of $80 \%$ (Fig. 2).

Codes d230 (carrying out daily routine), d430 (lifting and carrying objects), d770 (intimate relationships), d850 (remunerative employment), e165 (assets), and e540 (transportation services, systems, and policies), showed larger prevalences for positive answers for questions considering them, varying between 47.1 to $71.4 \%$. Code $\mathrm{d} 920$ (recreation and leisure) presented a bigger prevalence of intermediate answers (36.2\%). For codes e355 (support and relationships of health professionals) and e580 (health services, systems, and policies), we found a prevalence of positive answers of $61.0 \%$ (Fig. 2).

According to the DASH, code $\mathrm{d} 445$ (hand and arm use) was considered by 25 questions that presented high prevalences of positive answers, except for questions $1,7,8,11$, 
Table 2. Socioeconomic, clinical, and therapeutic variables

\begin{tabular}{|c|c|c|}
\hline Variables & $\mathrm{N}$ & $\%$ \\
\hline \multicolumn{3}{|l|}{ Age (years) } \\
\hline Up to 50 & 41 & 39.0 \\
\hline 51 or more & 64 & 61.0 \\
\hline \multicolumn{3}{|l|}{ Marital status } \\
\hline With partner & 51 & 48.6 \\
\hline Without a partner & 54 & 51.4 \\
\hline \multicolumn{3}{|l|}{ Level of education } \\
\hline Low level & 55 & 52.4 \\
\hline High level & 50 & 47.6 \\
\hline \multicolumn{3}{|l|}{ Occupation } \\
\hline Housewife & 63 & 60.0 \\
\hline Works outside the home & 42 & 40.0 \\
\hline \multicolumn{3}{|l|}{ Social Security } \\
\hline Economically active unemployed & 80 & 80.8 \\
\hline Economically active occupied & 19 & 19.2 \\
\hline \multicolumn{3}{|l|}{ Family income } \\
\hline Up to 2 minimum wages & 57 & 54.3 \\
\hline Above 2 minimum wages & 48 & 45.7 \\
\hline \multicolumn{3}{|l|}{ Social class } \\
\hline Class A & 1 & 1.0 \\
\hline Class B & 2 & 1.9 \\
\hline Class C & 13 & 12.4 \\
\hline Class D & 32 & 30.5 \\
\hline Class E & 57 & 54.3 \\
\hline \multicolumn{3}{|l|}{ BMI } \\
\hline Eutrophic & 26 & 27.4 \\
\hline Overweight & 43 & 45.3 \\
\hline Obese & 26 & 27.4 \\
\hline \multicolumn{3}{|l|}{ Clinical staging } \\
\hline Early stage (I-IIB) & 73 & 69.5 \\
\hline Advanced stage(III-IV) & 32 & 30.5 \\
\hline \multicolumn{3}{|l|}{ Follow-up after surgery } \\
\hline$<2$ years & 69 & 65.7 \\
\hline$>2$ years & 36 & 34.3 \\
\hline \multicolumn{3}{|l|}{ Type of Surgery } \\
\hline Mastectomy & 82 & 78.1 \\
\hline Conservative & 23 & 21.9 \\
\hline \multicolumn{3}{|l|}{ Axillary approach } \\
\hline SLN & 29 & 27.6 \\
\hline Axillary dissection & 76 & 72.4 \\
\hline \multicolumn{3}{|l|}{ Reconstruction } \\
\hline Yes & 5 & 6.2 \\
\hline No & 76 & 93.8 \\
\hline \multicolumn{3}{|l|}{ Seroma } \\
\hline Yes & 45 & 42.9 \\
\hline No & 60 & 57.1 \\
\hline \multicolumn{3}{|l|}{ Wound dehiscence and Necrosis } \\
\hline Yes & 30 & 28.8 \\
\hline No & 74 & 71.2 \\
\hline
\end{tabular}

$\mathrm{BMI}=$ body mass index, $\mathrm{SLN}=$ sentinel lymph node and 18 , which pertain to performance of heavy activities with the member. Codes d430, d640 (doing housework), d650 (caring for household objects), and d920, when measured by questions like these, presented higher prevalences of negative answers: $61.0 \%, 63.8 \%, 56.2 \%$, and $52.4 \%$, respectively. Codes d430, d640, and d920 were even considered by other questions, which, showed high prevalences of positive answers. For the other questions that measure code $\mathrm{d} 445$, we also found high prevalences of positive answers, except for the question related to "opening a tight jar" (44\% negative answers). Codes b265 (touch function) and b840 (sensation related to the skin), measured by the same questions in the DASH, and b730 (muscle power functions) presented prevalences of $67.6 \%$ and $76.2 \%$ positive answers, respectively (Fig. 3). It is important to raise that codes b126, b134, b430, d720, d750, d760, d770, d850 and d920 were also measured by WHOQOL, as related previously.

For code b455 (exercise tolerance functions), we could observe by the hand press test, low functional capacity in $57.1 \%$ of the cases. For, codes b730 (muscle power functions) and b740 (muscle endurance functions), $72.4 \%$ of the cases presented low functional capacity of the affected member in this test, showing a contradictory discovery compared with the DASH ones. The weight maintenance functions (b530) were examined using BMI data (data not show).

In the physical exam, a prevalence of $17.1 \%$ was observed for cases of winged scapula diagnosis, which is compatible with code b720 (mobility of bone functions). Regarding code e115 (products and technology for personal use in daily living), $78.1 \%$ of the women had received external breast prostheses. Codes b710 (mobility of joint functions), s720 (structure of shoulder region), and s730 (structure of upper extremity) presented low prevalences of incomplete arch of movement. The presence of fibrosis lymphatic was compatible with measurement of codes s420 (structure of immune system) and s4200 (lymphatic vessels), and 99\% of the population in this study did not present this alteration. None of the women presented lymphedema. For the measurement of codes b435 (immunological system functions), b4352, and b4353 (functions of lymphatic vessels and functions of lymph nodes), indirect volumetric data were used (data not show).

Codes e310 (support and relationships given by immediate family); e315, e320, e325, and e340 (support and relationship from personal care providers and personal assistants); e450 (individual attitudes of health professionals); and e465 (social norms, practices, and ideologies) were measured by the SSQ, in which we had higher concentration of answers in the third tertile of affective, emotional, information, and social positive interaction, corresponding to positive responses. Monetary support was measured with the SSQ, which showed larger monetary support; however, a larger prevalence was also observed in the first tertile, $32.5 \%$, indicating low social support (Fig. 4).

\section{DISCUSSION}

The results obtained in this work pertain to the analysis of women from only one public treatment center that is a 


\begin{tabular}{|c|c|c|c|c|c|c|c|c|c|c|c|c|}
\hline \multirow[t]{3}{*}{ WHOQOL (questions) } & \multicolumn{3}{|c|}{$\begin{array}{c}\text { WHOQOL } \\
\text { categories } \\
(\%)\end{array}$} & \multicolumn{9}{|c|}{ ICF codes } \\
\hline & \multirow{2}{*}{$\begin{array}{c}\text { Cat } \\
1\end{array}$} & \multirow{2}{*}{$\begin{array}{c}\text { Cat } \\
2\end{array}$} & \multirow{2}{*}{\begin{tabular}{c|c} 
Cat \\
3
\end{tabular}} & \multicolumn{9}{|c|}{ Body functions } \\
\hline & & & & \multicolumn{6}{|c|}{ b1 } & b2 & \multicolumn{2}{|c|}{ b6 } \\
\hline $\begin{array}{l}\text { pain prevents you from doing what you need } \\
\text { to do?) }\end{array}$ & 53.8 & 23.1 & 23.1 & & & & & & & b280 & & \\
\hline $\begin{array}{l}\text { WQ4 (How much do you need any medical } \\
\text { treatment to function in your daily life?) }\end{array}$ & 40.0 & 28.6 & 31.4 & & & & & & & & & \\
\hline WQ5 (How much do you enjoy life?) & 19.0 & 25.7 & 55.2 & b126 & b130 & & & & & & & \\
\hline $\begin{array}{l}\text { WQ6 (To what extent do you feel your life to } \\
\text { be meaningful?) }\end{array}$ & & & & & & & & & & & & \\
\hline WQ7 (How well are you able to concentrate?) & 15.2 & 32.4 & 52.4 & & & & & & & & & \\
\hline $\begin{array}{l}\text { WQ8 (Quão segura você se sente na sua vida } \\
\text { diária?) }\end{array}$ & 6.7 & 26.7 & 66.7 & b126 & & & & & & & & \\
\hline $\begin{array}{l}\text { WQ9 (How healthy is your physical } \\
\text { environment?) }\end{array}$ & 13.3 & 25.7 & 61.0 & & & & & & & & & \\
\hline $\begin{array}{l}\text { WQ10 (Do you have enough energy for } \\
\text { everyday life?) }\end{array}$ & 9.5 & 42.9 & 47.6 & & b130 & & & & & & & \\
\hline $\begin{array}{l}\text { WQ11 (Are you able to accept your bodily } \\
\text { appearance?) }\end{array}$ & 19 & 21.9 & 59.1 & & & & & & b1801 & & & \\
\hline $\begin{array}{l}\text { WQ12 (Have you enough money to meet your } \\
\text { needs?) }\end{array}$ & 52.4 & 25.7 & 21.9 & & & & & & & & & \\
\hline $\begin{array}{l}\text { WQ13 (How available to you is the } \\
\text { information that you need in your day-to-day } \\
\text { life?) }\end{array}$ & & & & & & & & & & & & \\
\hline $\begin{array}{l}\text { WQ14 (To what extent do you have the } \\
\text { opportunity for leisure activities?) }\end{array}$ & 31.4 & 36.2 & 32.4 & & & & & & & & & \\
\hline WQ15 (How well are you able to get around?) & 6.7 & 21.9 & 71.4 & & & & & & & & & \\
\hline $\begin{array}{l}\text { WQ16 (How satisfied are you with your } \\
\text { sleep?) }\end{array}$ & 21 & 15.2 & 63.8 & & & b134 & b152 & & & & & \\
\hline $\begin{array}{l}\text { WQ17 (How satisfied are you with your } \\
\text { ability to perform your daily living activities?) }\end{array}$ & 18.1 & 21.9 & 60.0 & & & & b152 & & & & & \\
\hline $\begin{array}{l}\text { WQ18 (How satisfied are you with your } \\
\text { capacity for work?) }\end{array}$ & 30.5 & 20.0 & 49.5 & & & & b152 & & & & & \\
\hline WQ19 (How satisfied are you with yourself?) & 15.2 & 10.5 & 74.3 & & & & b152 & b180 & & & & \\
\hline $\begin{array}{l}\text { WQ } 20 \text { (How satisfied are you with your } \\
\text { personal relationships?) }\end{array}$ & 4.8 & 13.3 & 81.9 & & & & b152 & & & & & \\
\hline $\begin{array}{l}\text { WQ21 (How satisfied are you with your sex } \\
\text { life?) }\end{array}$ & 27.9 & 25.0 & 47.1 & & & & b152 & & & & b640 & $b 670$ \\
\hline $\begin{array}{l}\text { WQ22 (How satisfied are you with the support } \\
\text { you get from your friends?) }\end{array}$ & 5.7 & 14.3 & 80.0 & & & & b152 & & & & & \\
\hline $\begin{array}{l}\text { WQ23 (How satisfied are you with the } \\
\text { conditions of your living place?) }\end{array}$ & 21.9 & 18.1 & 60.0 & & & & b152 & & & & & \\
\hline $\begin{array}{l}\text { WQ24 (How satisfied are you with your } \\
\text { access to health services?) }\end{array}$ & 22.9 & 16.2 & 61.0 & & & & b152 & & & & & \\
\hline $\begin{array}{l}\text { WQ25 (How satisfied are you with your } \\
\text { transport?) }\end{array}$ & 28.6 & 22.9 & 48.6 & & & & b152 & & & & & \\
\hline $\begin{array}{l}\text { WQ26 (How often do you have negative } \\
\text { feelings such as blue mood, despair, anxiety, } \\
\text { depression?) }\end{array}$ & 77.1 & 9.5 & 13.3 & & & & b152 & & & & & \\
\hline
\end{tabular}

cat $1=1$ st category answers $(1$ e 2$)$, cat $2=2$ nd category answers (3), cat $3=3$ rd category answers $(4$ e 5$), W Q=$ WHOQOL brief question

Fig. 1. Prevalence of the body function ICF codes by questions of the WHOQOL

reference hospital in the city of Rio de Janeiro and prioritizes physiotherapy treatment based on all its phases during oncological treatment; however, they may not represent the results for women in the general population who have undergone breast cancer treatment.

The demographic characteristics of the studied population are compatible with the data from other Brazilian studies that have evaluated women after breast cancer ${ }^{27-29)}$. The clinical and surgical findings are also a picture of the Brazilian population diagnosed and treated for this disease ${ }^{30,31)}$.

In this study, clinical evaluation instruments compatible with the most prevalent ICF codes for the famale population with a breast cancer diagnosis according to Brach et al. ${ }^{11)}$, were applied to evaluate the prevalence of each code.
The prevalence of favorable answers for temperament and personality functions (b126), energy and drive functions (b130), and emotional functions (b152) can demonstrate a low tendency for depressive symptoms or difficulty in relating such symptoms to the examiner. According to Den Oudsten et al. ${ }^{32}$, factors related to personality are responsible for depressive symptoms one year after surgery for breast cancer treatment. These factorscould be related to age, previous cognitive changes, and system treatment ${ }^{33)}$.

According to Grossman et al. ${ }^{34)}$, contrary to what we observed in our study, women with breast cancer stated more dissatisfaction, reported a lack of energy and had a greater probability for negative feelings than healthy controls. Reid-Arndt et al. ${ }^{35}$ ) found a relation between depres- 


\begin{tabular}{|c|c|c|c|c|c|c|c|c|c|c|c|c|c|c|c|c|c|c|c|}
\hline \multirow{4}{*}{\begin{tabular}{|l} 
WHOQOL (questions) \\
$\begin{array}{l}\text { WQ3 (To what extent do you feel that physical pain prevents } \\
\text { you from doing what you need to do?) }\end{array}$ \\
\end{tabular}} & \multirow{2}{*}{\multicolumn{3}{|c|}{$\begin{array}{l}\text { WHOQOL } \\
\text { (\% answers) }\end{array}$}} & \multicolumn{16}{|c|}{ CIF codes } \\
\hline & & & & \multicolumn{7}{|c|}{ Activities \& Participation } & \multicolumn{9}{|c|}{ Environmental Factors } \\
\hline & \multirow{2}{*}{\begin{tabular}{|l} 
cat 1 \\
53.8 \\
\end{tabular}} & \multirow{2}{*}{\begin{tabular}{|l} 
cat 2 \\
23.1 \\
\end{tabular}} & \multirow{2}{*}{\begin{tabular}{l|} 
cat 3 \\
23.1 \\
\end{tabular}} & \multirow[t]{2}{*}{ d2 2} & \multirow[t]{2}{*}{ d4 } & \multicolumn{3}{|c|}{ d7 } & \multirow[t]{2}{*}{ d8 } & \multirow[t]{2}{*}{ d9 } & \multirow[t]{2}{*}{ e1 } & \multirow[t]{2}{*}{ e2 } & \multicolumn{3}{|c|}{ e3 } & \multicolumn{3}{|c|}{ e4 } & \multirow[t]{2}{*}{ e5 } \\
\hline & & & & & & & & & & & & & & & & & & & \\
\hline $\begin{array}{l}\text { WQ4 (How much do you need any medical treatment to } \\
\text { function in your daily life?) }\end{array}$ & 40.0 & 28.6 & 31.4 & & & & & & & & e110 & & e 355 & & & & & & \\
\hline WQ5 (How much do you enjoy life?) & 19.0 & 25.7 & 55.2 & & & & & & & & & & & & & & & & \\
\hline \multicolumn{20}{|l|}{$\begin{array}{l}\text { WQ6 (To what extent do you feel your life to be } \\
\text { meaningful?) }\end{array}$} \\
\hline WQ7 (How well are you able to concentrate?) & 15.2 & 32.4 & 52.4 & $\mathrm{~d} 240$ & & & & & & & & & & & & & & & \\
\hline WQ8 (How safe do you feel in your daily life?) & 6.7 & 26.7 & 66.7 & & & & & & & & & & & & & & & & \\
\hline WQ9 (How healthy is your physical environment?) & 13.3 & 25.7 & 61.0 & & & & & & & & & e225 & & & & & & & \\
\hline WQ10 (Do you have enough energy for everyday life?) & 9.5 & 42.9 & 47.6 & & & & & & & & & & & & & & & & \\
\hline \multicolumn{20}{|l|}{ WQ11 (Are you able to accept your bodily appearance?) } \\
\hline WQ12 (Have you enough money to meet your needs?) & 52.4 & 25.7 & 21.9 & & & & & & & & e165 & & & & & & & & \\
\hline \multicolumn{20}{|l|}{$\begin{array}{l}\text { WQ13 (How available to you is the information that you need } \\
\text { in your day-to-day life?) }\end{array}$} \\
\hline $\begin{array}{l}\text { WQ14 (To what extent do you have the opportunity for } \\
\text { leisure activities?) }\end{array}$ & 31.4 & 36.2 & 32.4 & & & & & & & d920 & & & & & & & & & \\
\hline WQ15 (How well are you able to get around?) & 6.7 & 21.9 & 71.4 & & $\mathrm{~d} 430$ & & & & & & & & & & & & & & \\
\hline WQ16 (How satisfied are you with your sleep) & 21 & 15.2 & 63.8 & & & & & & & & & & & & & & & & \\
\hline $\begin{array}{l}\text { WQ17 (How satisfied are you with your ability to perform } \\
\text { your daily living activities?) }\end{array}$ & 18.1 & 21.9 & 60.0 & $\mathrm{~d} 230$ & & & & & & & & & & & & & & & \\
\hline WQ18 (How satisfied are you with your capacity for work?) & 30.5 & 20.5 & 49.5 & & & & & & d 850 & & & & & & & & & & \\
\hline WQ19 (How satisfied are you with yourself?) & 15.2 & 10.5 & 74.3 & & & & & & & & & & & & & & & & \\
\hline $\begin{array}{l}\text { WQ } 20 \text { (How satisfied are you with your personal } \\
\text { relationships?) }\end{array}$ & 4.8 & 13.3 & 81.9 & & & d720 & d750 & d760 & & & & & e315 & e320 & e325 & e415 & e 420 & e425 & \\
\hline WQ21 (How satisfied are you with your sex life?) & 27.9 & 25.0 & 47.1 & & & d770 & & & & & & & & & & & & & \\
\hline $\begin{array}{l}\text { WQ22 (How satisfied are you with the support you get from } \\
\text { your friends?) }\end{array}$ & 5.7 & 14.3 & 80.0 & & & & & & & & & & e320 & & & $\mathrm{e} 420$ & & & \\
\hline $\begin{array}{l}\text { WQ23 (How satisfied are you with the conditions of your } \\
\text { living place?) }\end{array}$ & 21.9 & 18.1 & 60.0 & & & & & & & & e165 & & & & & & & & \\
\hline $\begin{array}{l}\text { WQ24 (How satisfied are you with your access to health } \\
\text { services?) }\end{array}$ & 22.9 & 16.2 & 61.0 & & & & & & & & & & e 355 & & & $\mathrm{e} 450$ & & & e 580 \\
\hline WQ25 (How satisfied are you with your transport?) & 28.6 & 22.9 & 48.6 & & & & & & & & & & & & & & & & e 540 \\
\hline $\begin{array}{l}\text { WQ26 (How often do you have negative feelings such as blue } \\
\text { mood, despair, anxiety, depression?) }\end{array}$ & 77.1 & 9.5 & 13.3 & & & & & & & & & & & & & & & & \\
\hline
\end{tabular}

Fig. 2. Prevalence of the activities and participation and environmental factors ICF codes by questions of the WHOQOL

sive feelings and hesitation to look for support in women undergoing chemotherapy treatment for 1, 6 and 12 months and that there was a significant association with low general satisfaction.

In our population, we could verify a high prevalence of positive answers regarding time and personal experience functions, although most of our subjects had been subjected to breast dissection without breast makeover. In further studies in groups of women who were subjected to different kinds of treatment, after adjusting raising confusion factors, we could verify that body image worsened in women who had undergone breast reconstruction compared with those who had undergone conservative treatment ${ }^{36)}$.

The change in sensory function was similar between the two instruments in relation to codes b265 and b840 due to intercostobrachial nerve injury. In the literature, the prevalence of such consequence using the same diagnosis method varies between $34.7 \%$ and $85.1 \%$ in women who have been subjected to surgical treatment ${ }^{37,38)}$.

The low prevalence regarding sensation of pain (b280) could indicate a short period of time after surgery in our population and is in accordance with the results of Vilholm et al. ${ }^{39)}$, who found that $6.0 \%$ of women relate feeling a lot of pain a year and a half after breast cancer surgery in their daily routine. For localized pain (b280), we found lower results compared with the findings from other study in a female population, in which the authors presented a prevalence of $60 \%$ of pain after 18 months in women subjected to axillary lymphadenectomy ${ }^{4}$.

After breast cancer surgery, one of the main complications is lymphedema due to axillary lymphatic obstruction caused by the surgery and/or radiotherapy ${ }^{6}$. We did not find lymphedema in the studied population however this might have been caused by the short period used to evaluation of the cases (1.63 months) after surgery.

The difficulty in performing certain activities might be a result of damaged functional capacity of muscles to perform exercises, muscle resistance, and activities related to muscle force evaluated by dynamometer palm pressure. According to studies in a fragile elderly population, the above 


\begin{tabular}{|c|c|c|c|c|c|c|c|c|c|c|c|c|c|c|c|c|}
\hline \multirow{3}{*}{ DASH (questions) } & \multicolumn{3}{|c|}{ DASH (\% answers) } & \multicolumn{13}{|c|}{ ICF codes } \\
\hline & \multirow[t]{2}{*}{ Cat 1} & \multirow[t]{2}{*}{ Cat 2} & \multirow[t]{2}{*}{ Cat 3} & \multicolumn{4}{|c|}{ Body functions } & \multicolumn{9}{|c|}{ Activities and participation } \\
\hline & & & & b1 & b2 & b7 & b8 & \multicolumn{2}{|c|}{ d4 } & d5 & d6 & \multicolumn{3}{|c|}{ d7 } & d8 & d9 \\
\hline DQ1 (Open a tight jar) & 41.0 & 15.2 & $43.8^{*}$ & & & & & & $\mathrm{~d} 445$ & & & & & & & \\
\hline DQ2 (Write) & 84.8 & 8.6 & 6.7 & & & & & & d4445 & & & & & & & \\
\hline DQ3 (Turn a key) & 95.2 & 3.8 & 1.0 & & & & & & d 445 & & & & & & & \\
\hline DQ4 (Cook a meal) & 92.4 & 3.8 & 3.8 & & & & & & $\mathrm{~d} 445$ & & $\mathrm{~d} 630$ & & & & & \\
\hline DQ5 (Push open a heavy door) & 49.5 & 10.5 & 40.0 & & & & & & $\mathrm{~d} 445$ & & & & & & & \\
\hline DQ6 (Place an object on a shelf above your head) & 67.6 & 10.5 & 21.9 & & & & & $\mathrm{~d} 430$ & d 445 & & & & & & & \\
\hline DQ7 (Do heavy housework (wash walls, wash floor) & 24.8 & 11.4 & $63.8^{*}$ & & & & & & $\mathrm{~d} 445$ & & d640 & & & & & \\
\hline DQ8 (Gardening) & 36.2 & 7.6 & $56.2 *$ & & & & & & $\mathrm{~d} 445$ & & d 650 & & & & & \\
\hline DQ9 (Make the bed) & 88.6 & 7.6 & 3.8 & & & & & & $\mathrm{~d} 445$ & & d 640 & & & & & \\
\hline DQ10 (Carry a heavy bag or a suitcase) & 77.1 & 11.4 & 11.4 & & & & & $\mathrm{~d} 430$ & $\mathrm{~d} 445$ & & & & & & & \\
\hline DQ11 (Carry a heavy object (more than $5 \mathrm{~kg}$ )) & 31.4 & 7.6 & $61.0^{*}$ & & & & & $\mathrm{~d} 430$ & $\mathrm{~d} 445$ & & & & & & & \\
\hline DQ12 (Change a light bulb above your head) & 57.1 & 3.8 & 39.0 & & & & & & $\mathrm{~d} 445$ & & & & & & & \\
\hline DQ13 (Wash or dry your hair) & 95.2 & 2.9 & 1.9 & & & & & & $\mathrm{~d} 445$ & $\mathrm{~d} 510$ & & & & & & \\
\hline DQ14 (Wash your back) & 80.0 & 6.7 & 13.3 & & & & & & $\mathrm{~d} 445$ & $\mathrm{~d} 510$ & & & & & & \\
\hline DQ15 (Put on a sweater) & 81.0 & 9.5 & 9.5 & & & & & & $\mathrm{~d} 445$ & $\mathrm{~d} 540$ & & & & & & \\
\hline DQ16 (Use a knife to cut food) & 84.8 & 5.7 & 9.5 & & & & & & $\mathrm{~d} 445$ & d550 & & & & & & \\
\hline DQ17 (Recreational activities (play cards. knit)) & 81.0 & 3.8 & 15.2 & & & & & & & $\mathrm{~d} 445$ & & & & & & d 920 \\
\hline $\begin{array}{l}\text { DQ18 (Recreational activities, which cause impact in } \\
\text { your arms, Shoulders, and hands (play volleyball, } \\
\text { hammering)) }\end{array}$ & 39.0 & 8.6 & $52.4^{*}$ & & & & & & & $\mathrm{~d} 445$ & & & & & & d920 \\
\hline $\begin{array}{l}\text { DQ19 (Recreational activities in which you move your } \\
\text { arm freely (fishing, badminton)) }\end{array}$ & 77.1 & 6.7 & 16.2 & & & & & & & $\mathrm{~d} 445$ & & & & & & d 920 \\
\hline DQ20 (Handle transportation needs) & 88.6 & 5.7 & 5.7 & & & & & & 30 & & d 445 & & & & & \\
\hline DQ21 (Sexual activities) & 57.3 & 6.8 & 35.9 & & & & & & & $\mathrm{~d} 445$ & & d770 & & & & \\
\hline $\begin{array}{l}\text { DQ22 (Last week, how much has your problem affected } \\
\text { your regular activities with family, friends, neighbors, or } \\
\text { groups?) }\end{array}$ & 81.9 & 8.6 & 9.5 & & & & & & & d445 & & d7 20 & d750 & d760 & & \\
\hline $\begin{array}{l}\text { DQ23 (During last week, was your work or regular } \\
\text { activities limited because of your problem?) }\end{array}$ & 68.6 & 19.0 & 12.4 & & & & & & & d445 & & & & & d850 & \\
\hline DQ24 (Pain in the arm, shoulder, or hand) & 66.7 & 21.0 & 12.4 & & b2801 & & & & & & & & & & & \\
\hline $\begin{array}{l}\text { DQ25 (Pain in the arm, shoulder, or hand while doing } \\
\text { specific activities) }\end{array}$ & 67.6 & 18.1 & 14.3 & & b2801 & & & & & d445 & & & & & & \\
\hline DQ26 (Pins and needles in your arm, shoulder, or hand) & 67.6 & 20.0 & 12.4 & & b265 & & b840 & & & & & & & & & \\
\hline DQ27 (Weakness in the arm, shoulder, or hand) & 76.2 & 13.3 & 10.5 & & & b730 & & & & & & & & & & \\
\hline DQ28 (Difficulty in moving the arm, shoulder, or hand) & 75.2 & 13.3 & 11.4 & & & b710 & & & & $\mathrm{d} 445$ & & & & & & \\
\hline $\begin{array}{l}\text { DQ29 (During last week, how difficult was it for you to } \\
\text { sleep because of the pain in your arm, shoulder, or hand?) }\end{array}$ & 67.6 & 18.1 & 14.3 & b134 & b2801 & & & & & & & & & & & \\
\hline $\begin{array}{l}\text { DQ30 (I feel less capable, confident, and useful because } \\
\text { of my problem) }\end{array}$ & 50.5 & 17.1 & 32.4 & b126 & & & & & & & & & & & & \\
\hline
\end{tabular}

Fig. 3. Prevalence of the body functions and activities and participation ICF codes in the DASH

\begin{tabular}{|c|c|c|c|c|}
\hline \multirow{3}{*}{ Social Support (domínios) } & \multirow{2}{*}{\multicolumn{3}{|c|}{ Social Support - answers (\%) }} & ICF codes \\
\hline & & & & Environmental factors \\
\hline & 1st tertile & 2nd tertile & 3rdtertile & \multirow{6}{*}{$\begin{array}{l}\text { e310. e315. e320. e325. } \\
\text { e340. e355. e410. e415. } \\
\text { e420. e425. e440. e450. } \\
\text { e465 }\end{array}$} \\
\hline Material support & 35.2 & 32.4 & 32.4 & \\
\hline Affective support & & & 100.0 & \\
\hline Emotional support & & 33.3 & 66.7 & \\
\hline Information support & & 36.2 & 63.8 & \\
\hline Positive social interaction & & 41.0 & 59.0 & \\
\hline
\end{tabular}

Fig. 4. Prevalence of environmental ICF codes for social supports questions

might cause poor performance in motor activities and poor general health as well ${ }^{16)}$. Although we have the DASH as an alternative way to measure code b730 code, the dynamometer palm pressure seems to be more trustworthy. For this reason, further studies are necessary to evaluate this aspect using both instruments.

Range of motion (b710) might be damaged in women subjected to surgical treatment for breast cancer; however, there was a higher prevalence of normal extension in our study. Nesvold et al. ${ }^{40)}$ found a huge prevalence of altera- 
tions in the ADM to flexion and abduction after four years of treatment not only in women subjected to breast dissection but also in a group subjected to conservative surgery.

Looking at the findings in the literature, the evaluation of scapular stability (b720) showed a high prevalence of winged scapula in the cases. In a study performed in women with advanced breast cancer, sequelae occurred less frequently even though the treatment had been wider and more invasive $^{41)}$. Another study showed a low prevalence of web syndrome (s4200), and this kind of complication was expected due to observation a couple of weeks after surgery ${ }^{21)}$.

The higher prevalence of cases with negative answers regarding the ability to carry heavy objects and do more complex movements might be related to the fact that patients avoid doing them so that they do not develop lymphedema and other sequelae.

In another study, favorable answers were observed for ICF code d630 (preparing meals), which is related to daily chores, according to the recommendations to avoid heat or contact with hot surfaces, which might cause risks of lymphedema ${ }^{13)}$.

In our evaluation of codes related to interpersonal interactions and relationships (d720, d750, d760, and d770), we observed a higher prevalence of positive answers. This was also the case for the measure of sexual functions (b640) and sensations associated with reproductive and genital functions (b670) through the quality of life questionnaire, which is used to investigate a patient's satisfaction about sexual life. Ganz et al. ${ }^{42)}$ have previously related alterations in social functioning and sexual activity in a study of breast cancer survivors more than 5 to 10 years after diagnosis. According to Perez et $\mathrm{al}^{43)}$, these dysfunctions should be associated with psychosocial factors such as humor and body image alterations and also menopause symptoms and not exactly to the kind of surgery done in women diagnosed in an early stage of disease.

Regarding jobs (d850), positive answers about satisfaction with the capacity for work have been reported. Hasset et al. ${ }^{44)}$ observed incapacity, interruption of work, and early retirement among women who were subjected to chemotherapy. A wider study done in a population with different kinds of cancer showed the same results ${ }^{45}$. The financial impact in the USA resulting from cancer was reported in the study of Bradley et al. ${ }^{46}$, which predicts prevention measures for the disease in the younger economically active population. In Brazil, breast cancer has presented the highest rate of incidence $(61.9: 100,000)$ among sickness benefitsgiven in 2006, compared to all the others in different localizations (by age) ${ }^{47}$, which represented a high impact in the social security.

Regarding the code concerning products or substances for personal consumption (e110), which was evaluated according to the women's dependence on medical treatment on a daily basis, although positive answers prevailed, many women reported being dependent on their treatment, which may explain the usage of hormone therapy in the period of collection. All the women subjected to mastectomy received external silicon prostheses, which may justify the high prevalence of this support in the studied women ${ }^{13)}$.
The prevalence of negative answers for material support (35.2\% for the codes related to individual activities and family, friends, community, and other relationships) corresponds to the data found in literature, which suggested a potential deleterious impact caused not only in the patient by the disease but also in members of their social net ${ }^{48)}$. Therefore, it is necessary to invest in services that are able to evaluate and follow the conditions of those who deal with oncological patients.

Codes e315, e320, e325, e415, e420, and e425 can be economically measured by the WHOQOL with the question that evaluates the satisfaction with personal relationships, which showed a higher prevalence of cases with positive answers $(81.9 \%)$, but this was not reflected in the findings of another instrument, which has already been mentioned. In the WHOQOL, similarity was noted for codes e355, e455, and e580 concerning measurement of how satisfied individuals were with their access to health services, presenting prevalences of favorable answers of $61.0 \%$. The fact that the study was performed in a reference hospital from the public system, with multidisciplinary support and well established protocols of assistance, may justify these findings.

The concept of disease/incapacity may determine what we consider a limit of responsibility for health professionals that influence their behavior ${ }^{49)}$. This behavior may extend to family and other members of society who interact with the individual, besides the policy and organization systems around them.

The transportation services, systems, and policies (e540) and health services, systems, and policies (e580) balance with two distinct questions from the WHOQOL. The first code may be measured through satisfaction with the used means of transportation through which we found that the higher prevalences of negative and intermediate answers, the higher the prevalence was for women who need to make more than two trips to get in the hospital.

Although the SSQ has become better at measuring ICF codes and collecting data about family support or an individual's social life, it may inform us about the kind of support, regardless the kind of social relationships that the individual might have with other people. The research about the kind of support, and not who supplies it, seems to us to be more similar to the individuals' needs.

The low prevalence of findings from the current study may reflect the short period after surgery. Besides, the study was performed in a reference hospital, with qualified professional staff who approach patients right before surgery with recommendations and care, trying to identify comorbidities that might be able to decrease functionality ${ }^{13)}$.

In conclusion, the population studied in this research presented low functional disability for most of the constructs evaluated, showing the necessity of physical therapy intervention in the first phases of oncological treatment. However, the short period after surgery may be a main factor in these findings, as long-term follow-up is necessary to better define the disability in this population. Use of the ICF for the population subjected to breast cancer treatment was possible due to the use of a large quantity of tools, which together considered about $70 \%$ of the Core Set proposed 
by such pathology. However, utilization of many tools is difficult when attempting to obtain information about individuals, and it may also entail a great deal of time to apply them, which would make it difficult in clinical practice. To overcome this limitation, most studies that propose more objective and able instruments to cover so many constructs of the ICF as included in this study are needed.

\section{ACKNOWLEDGEMENT}

We are grateful to the physiotherapy service of HC3.

\section{REFERENCES}

1) Instituto Nacional de Câncer José Alencar Gomes da Silva: Estimativa 2012 - Incidência de Câncer no Brasil. 2011. http://wwwl.inca.gov.br/estimativa/2012/estimativa20122111.pdf (Accessed Aug. 8, 2012)

2) Haddad CF: Radioterapia adjuvante no câncer de mama operável. Femina, 2011, 39: 295-302 (in portuguese)

3) Rietman JS, Dijkstra PU, Debreczeni R, et al.: Impairments, disabilitie and health related quality of life after treatment for breast cancer: a followup study 2.7 years after surgery. Disabil Rehabil, 2004, 26: 78-84. [Medline] [CrossRef

4) Magaldi CM, Barros AC, Magaldi FM, et al.: Avaliação da morbidade e funcionalidade do membro superior em mulheres submetidas à linfadenectomia axilar total e biópsia de linfonodo sentinela por câncer de mama. Rev Bras Mastol, 2005, 15: 9-14 (in portuguese).

5) Merchant CR, Chapman T, Kilbreath SL, et al.: Decreased muscle strength following management of breast cancer. Disabil Rehabil, 2008, 30: 10981105. [Medline] [CrossRef]

6) Bevilacqua JL, Kattan MW, Changhong Y, et al.: Nomograms for predicting the risk of arm lymphedema after axillary dissection in breast cancer Ann Surg Oncol, 2012, 19: 2580-2589. [Medline] [CrossRef]

7) Glaessel A, Kirchberger I, Stucki G, et al.: Does the Comprehensive International Classification of Functioning, Disability and Health (ICF) Core Set for Breast Cancer capture the problems in functioning treated by physiotherapists in women with breast cancer? Physiotherapy, 2011, 97: 33-46. [Medline] [CrossRef]

8) Velloso FS, Barra AA, Dias RC: Morbidade de Membros Superiores e Qualidade de Vida após a Biópsia de Linfonodo Sentinela para o Tratamento do Câncer de Mama. Rev Bras Cancerol, 2009, 55: 75-85 (in portuguese).

9) Biral S.: CIF: Classificação Internacional de Funcionalidade, Incapacidade e Saúde. São Paulo: EDUSP, 2008, pp 1-328.

10) Cieza A, Stucki G: Content comparison of health-related quality of life (HRQOL) instruments based on the international classification of functioning, disability and health (ICF). Qual Life Res, 2005, 14: 1225-1237. [Medline] [CrossRef]

11) Brach M, Cieza A, Stucki G, et al.: ICF Core Sets for breast cancer. J Rehabil Med, 2004, 44: 121-127. [Medline] [CrossRef]

12) Carvalho FN, Koifman RJ, Bergmann A: International Classification of Functioning, Disability, and Health in women with breast cancer: a proposal for measurement instruments. Cad Saude Publica, 2013, 29: 10831093. [Medline] [CrossRef]

13) Bergmann A, Ribeiro MJ, Pedrosa E., et al.: Physical therapy in breast cancer: clinical protocol at the Cancer Hospital III / INCA. Rev Bras Cancerol, 2006, 52: 97-109.

14) Instituto Brasileiro de Geografia e Estatística. Indicadores de Desenvolvimento Sustentável. Estudos e Pesquisas. Informação Geográfica. http:// www.ibge.gov.br/home/geociencias/recursosnaturais/ids/ids2010.pdf (accessed Apr. 10, 2012)

15) Instituto Nacional de Câncer: TNM: Classificação de tumores malignos, 6th ed. Rio de Janeiro (RJ): INCA, 2004, pp 1-254.

16) Geraldes AA, Oliveira AR, Albuquerque RB, et al.: A força de preensão manual é boa preditora do desempenho funcional de idosos frágeis: um estudo correlacional múltiplo. Rev Bras Med Esporte, 2008, 14: 12-16. [CrossRef]

17) Reis MM: Estudo de validade e confiabilidade entre os dinamômetros Saehan e Jamar [dissertação]. São José dos Campos (SP): Universidade do Vale do Paraíba; 2009. p 78.

18) Armer JM, Radina ME, Porock D, et al.: Predicting breast cancer-related lymphedema using self-reported symptoms. Nurs Res, 2003, 52: 370-379.
[Medline] [CrossRef]

19) Norman SA, Localio AR, Potashnik SL, et al.: Lymphedema in breast cancer survivors: incidence, degree, time course, treatment, and symptoms. J Clin Oncol, 2009, 27: 390-397. [Medline] [CrossRef]

20) Oliveira JF, Pereira TB, Dias RA, et al.: Incidence and risk factors of winged scapula after axillary lymph node dissection in breast cancer surgery. Appl Cancer Res, 2009, 29: 69-73.

21) Bergmann A, Mendes VV, de Almeida Dias R, et al.: Incidence and risk factors for axillary web syndrome after breast cancer surgery. Breast Cancer Res Treat, 2012, 131: 987-992. [Medline] [CrossRef]

22) Ferreira BP, Pimentel MD, Santos LC, et al.: [Morbidity after sentinel node biopsy and axillary dissection in breast cancer]. Rev Assoc Med Bras, 2008, 54: 517-521. [Medline] [CrossRef]

23) WHOQOL-bref: Introduction, administration, scoring and generic version of the assessment. Programme on mental health world health organization. Geneva: World Health Organization Group, 1996.

24) Griep RH, Dóra C, Faerstein E, et al.: [Test-retest reliability of measures of social network in the "Pró -Saúde" Study]. Rev Saude Publica, 2003, 37: 379-385. [Medline] [CrossRef]

25) Andrade CR, Chor D, Faerstein E, et al.: [Social support and breast self-examination in the Pró-Saúde Study]. Cad Saude Publica, 2005, 21: 379-386. [Medline] [CrossRef]

26) Orfale AG, Araújo PM, Ferraz MB, et al.: Translation into Brazilian Portuguese, cultural adaptation and evaluation of the reliability of the Disabilities of the Arm, Shoulder and Hand Questionnaire. Braz J Med Biol Res, 2005, 38: 293-302. [Medline] [CrossRef]

27) Moraes A, Zanini R, Turchiello M, et al.: Brasil Survival study of breast cancer patients treated at the hospital of the Federal University in Santa Maria, Rio G. do Sul. Cad Saude Publica, 2006, 22: 2219-2228. [Medline] [CrossRef]

28) Schneider IJ, d'Orsi E: [Five-year survival and prognostic factors in women with breast cancer in Santa Catarina State, Brazil]. Cad Saude Publica, 2009, 25: 1285-1296. [Medline] [CrossRef]

29) Gonçalves LL, Lima AV, Brito ES, et al.: Mulheres portadoras de câncer de mama: conhecimento e acesso às medidas de detecção precoce. Rev Enf, 2009, 17: 362-367.

30) Sclowitz ML, Menezes AM, Gigante DP, et al.: Condutas na prevenção secundária do câncer de mama e fatores associados. Rev Saude Publica, 2005, 39: 340-349. [Medline] [CrossRef]

31) Wünsch-Filho V, Antunes JL, Boing AF, et al.: Perspectivas da investigação sobre Determinantes Sociais em Câncer. Rev Saude Coletiva, 2008, 18: 427-450 (in portuguese).

32) Den Oudsten BL, Van Heck GL, Van der Steeg AF, et al.: Predictors of depressive symptoms 12 months after surgical treatment of early-stage breast cancer. Psychooncology, 2009, 18: 1230-1237. [Medline] [CrossRef]

33) Ahles TA, Saykin AJ, McDonald BC, et al.: Longitudinal assessment of cognitive changes associated with adjuvant treatment for breast cancer: impact of age and cognitive reserve. J Clin Oncol, 2010, 28: 4434-4440. [Medline] [CrossRef]

34) Grossman P, Deuring G, Garland SN, et al.: Patterns of objective physical functioning and perception of mood and fatigue in posttreatment breast cancer patients and healthy controls: an ambulatory psychophysiological investigation. Psychosom Med, 2008, 70: 819-828. [Medline] [CrossRef]

35) Reid-Arndt SA, Hsieh C, Perry MC: Neuropsychological functioning and quality of life during the first year after completing chemotherapy for breast cancer. Psychooncology, 2010, 19: 535-544. [Medline] [CrossRef]

36) Collins KK, Liu Y, Schootman M, et al.: Effects of breast cancer surgery and surgical side effects on body image over time. Breast Cancer Res Treat, 2011, 126: 167-176. [Medline] [CrossRef]

37) Pimentel MD, Santos LC, Gobbi H: Avaliação clínica da dor e sensibilidade cutânea de pacientes submetidas à dissecção axilar com preservação do nervo intercostobraquial para o tratamento cirúrgico do câncer de mama. Rev Bras Ginecol Obstet, 2007, 29: 291-296 (in portuguese). [CrossRef]

38) Santos MS, Panobianco MS, Mamede MV, et al.: Sensibilidade tátil no membro superior de mulheres submetidas à linfonodectomia axilar por câncer de mama. Rev Bras Ginecol Obstet, 2009, 31: 361-366 (in portuguese). [Medline] [CrossRef]

39) Vilholm OJ, Cold S, Rasmussen L, et al.: The postmastectomy pain syndrome: an epidemiological study on the prevalence of chronic pain after surgery for breast cancer. Br J Cancer, 2008, 99: 604-610. [Medline] [CrossRef]

40) Nesvold IL, Dahl AA, Løkkevik E, et al.: Arm and shoulder morbidity in breast cancer patients after breast-conserving therapy versus mastectomy. Acta Oncol, 2008, 47: 835-842. [Medline] [CrossRef]

41) Bergmann A, Bourrus NS, de Carvalho CM, et al.: Arm symptoms and 
overall survival in Brazilian patients with advanced breast cancer. Asian Pac J Cancer Prev, 2011, 12: 2939-2942. [Medline]

42) Ganz PA, Desmond KA, Leedham B, et al.: Quality of life in long-term, disease-free survivors of breast cancer: a follow-up study. J Natl Cancer Inst, 2002, 94: 39-49. [Medline] [CrossRef]

43) Pérez M, Liu Y, Schootman M, et al.: Changes in sexual problems over time in women with and without early-stage breast cancer. Menopause, 2010, 17: 924-937. [Medline] [CrossRef]

44) Hassett MJ, O'Malley AJ, Keating NL: Factors influencing changes in employment among women with newly diagnosed breast cancer. Cancer, 2009, 115: 2775-2782. [Medline] [CrossRef]

45) de Boer AG, Verbeek JH, Spelten ER, et al.: Work ability and returnto-work in cancer patients. Br J Cancer, 2008, 98: 1342-1347. [Medline] [CrossRef]
46) Bradley CJ, Yabroff KR, Dahman B, et al.: Productivity costs of cancer mortality in the United States: 2000-2020. J Natl Cancer Inst, 2008, 100: 1763-1770. [Medline] [CrossRef]

47) Marcelino MA: "Neoplasias malignas entre beneficiários da Previdência Social, com ênfase no auxílio-doença, Brasil, 2006" [dissertation]. Rio de Janeiro (RJ): Escola Nacional de Saúde Pública Sérgio Arouca, 2008, 123.

48) Arora NK, Finney Rutten LJ, Gustafson DH, et al.: Perceived helpfulness and impact of social support provided by family, friends, and health care providers to women newly diagnosed with breast cancer. Psychooncology, 2007, 16: 474-486. [Medline] [CrossRef]

49) Sampaio RF, Luz MT: [Human functioning and disability: exploring the scope of the World Health Organization's international classification]. Cad Saude Publica, 2009, 25: 475-483. [Medline] [CrossRef] 